\title{
Model Pembelajaran Induktif untuk Meningkatkan Pemahaman Konsep dan Keterampilan Generik Fisika Siswa SMA
}

\author{
Eko Swistoro Warimun ${ }^{1, a)}$, Astuti Murwaningsih ${ }^{2}$ \\ ${ }^{1}$ Program Studi Pendidikan Fisika FKIP Unib, Jl. WR. Supratman, Bengkulu \\ ${ }^{2}$ SMA Negeri 4 Kota Bengkulu, Jl. Zainul Arifin, Bengkulu \\ Email: a)eko_swistoro@yahoo.com
}

\begin{abstract}
The aim of the research was to know the improvement of concept understanding and physics generic skills of grade XII IPA 1 students in SMA Negeri 4 in Bengkulu City through Inductive Instruction Model for subject matter electromagnet. Metodology of this research is one group pretest-posttest design. The number of sampel is 32 student for the experiment class. Research data were collected by using paper and pencil test (pretest and posttest), physics generic skill test, and responses questionaire about the instruction model. Result of the research show that: 1) the instruction model can be increases the students' concept understanding with $\mathrm{N}$-gain is $0.67 ; 2$ ) $\mathrm{N}$-gain for physics generic skill is 0.67 for high group, 0.55 for medium group, and 0.46 for low group; and 3) Student were given good responses about the inductive instructional model.
\end{abstract}

Keywords: Inductive Instructional Model, Concept Understanding, Physics Generic Skills

\begin{abstract}
Abstrak
Penelitian ini bertujuan untuk meningkatkan Pemahaman Konsep dan Keterampilan Generik Fisika siswa SMA Negeri 4 Kota Bengkulu melalui model pembelajaran Induktif pada materi listrik-magnet, serta mengetahui tanggapan siswa terhadap pembelajaran model induktif. Penelitian dilakukan di kelas XII IPA1 ( $\mathrm{n}=32$ orang). Metode penelitian yang digunakan adalah one group pretest-posttest design.Data dikumpulkan dengan menggunakan tes pemahaman konsep dan tes keterampilan generik Fisika, serta angket tanggapan siswa terhadap pembelajaran. Hasil penelitian menunjukkan bahwa terjadi peningkatan pemahaman konsep yang diberikan dengan Ngain sebesar 0,67 (sedang). Peningkatan keterampilan generik fisika memberikan Ngain sebesar 0,67(sedang) untuk kelompok atas, 0,55 (sedang) untuk kelompok menengah, dan 0,46 (sedang) untuk kelompok bawah. Pembelajaran dengan model induktif mendapat tanggapan yang positif dari siswa.
\end{abstract}

Kata-kata kunci: Model Pembelajaran Induktif, Pemahaman Konsep, Keterampilan Generik Fisika 


\section{PENDAHULUAN}

Fisika adalah salah satu mata pelajaran penting di SMA. Agar hasil belajar siswa memuaskan, maka pembelajaran Fisika di SMA membutuhkan ketepatan dalam memilih model dan metode pembelajaran. Hal ini disebabkan karena dalam memilih model dan metode pembelajaran fisika harus disesuaikan dengan karakteristik materi fisika sesuai dengan kurikulum yang berlaku. Untuk tahun 2015 kelas XII SMA masih menggunakan kurikulum 2006 atau kurikulum tingkat satuan pendidikan (KTSP).

Kurikulum KTSP berorientasi pada pembelajaran yang berpusat kepada siswa, yang tujuannya agar siswa menguasai berbagai konsep dan prinsip fisika untuk mengembangkan pengetahuan, keterampilan, dan sikap sehingga dapat menerapkannya dalam kehidupan sehari-hari. Untuk meningkatkan pemahaman konsep fisika, guru harus memilih model dan metode pembelajaran yang tepat. Ada beberapa model pengajaran yang dapat mengaktifkan dalam belajar siswa, di antaranya adalah: 1) model pengajaran konvensional, 2) model pengajaran problem solving, 3) model pengajaran induktif, dan 4) model pengajaran deduktif (Sudjana, 1991). Untuk mbelajaran fisika di SMA untuk materi Listrik magnet dengan metode eksperimen dapat digunakan model pengajaran induktif. Dalam penelitian ini menggunakan model pengajaran/pembelajaran induktif dari Taba. Menurut Joice \& Weil (2011), model pembelajaran induktif Taba termasuk dalam model pembelajaran pemrosesan informasi. Model pembelajaran pemrosesan informasi menekankan pentingnya mendorong individu untuk memahami berbagai persoalan dengan cara mencari pemecahannya, serta mengembangkan pemahaman konsep dan bahasa sebagai alat untuk mengungkapkan persoalan yang dipelajari siswa.

Model berpikir induktif digunakan untuk meningkatkan efektivitas siswa dalam membangun konsep, dan mengembangkan keterampilan untuk menyelesaikan tugas (Joice \& Weil, 2011). Adapun langkah-langkah model pembelajaran induktif Taba adalah: 1) pembentukan konsep, 2) interpretasi data, dan 3) aplikasi prinsip. Sedangkan kegiatan pada tahap pembentukan kosep adalah mengidentifikasi dan menyebutkan satu persatu data yang relevan pada suatu topik atau masalah serta mengelompokkan objek-objek menjadi kategori-kategori yang anggotanya memiliki sifat yang umum. Kegiatan pada tahap interpretasi data, siswa mengidentifikasi/menafsirkan data dan mengembangkan label untuk kategori-kategori tadi sehingga data tersebut bisa dimanipulasi secara simbolis. Sedangkan untuk langkah apikasi prinsip adalah mengubah kategori-kategori tadi menjadi keterampilan atau hipotesis-hipotesis. Oleh karena itu berdasarkan langkah-langkah tersebut penulis melaksanakan pembelajaran model induktif dengan metode eksperimen.

Karakteristik yang dimiliki model pembelajaran induktif adalah: 1) digunakan untuk mengajarkan konsep dengan menggeneralisasi; 2) efektif untuk memotivasi siswa dalam pembelajaran; 3) menumbuhkan minat dan sikap siswa dalam melakukan observasi dan siswa diberi kesempatan untuk aktif; dan 4) mengembangkan keterampilan proses siswa dalam belajar. Untuk itulah model induktif ini dipilih dalam pembelajaran materi listrik magnet.

Materi listrik magnet mengandung konsep abstrak, sehingga memerlukan dukungan keterampilan berpikir yang komplek yaitu keterampilan generik fisika (KGF). Brotosiswojo (2000) menyatakan bahwa seyogyanya pembelajaran fisika menumbuhkan kemahiran generik. Indikator Keterampilan Generik Fisika menurut Brotosiswojo (2000) adalah pengamatan langsung, pengamatan tak langsung, kesadaran tentang skala besaran, bahasa simbolik, keranngka logika taat azas dan hukum alam, inferensi logika, hukum sebab akibat, pemodelan matematika, dan membangun konsep

Pentingnya pemahaman konsep dalam pembelajaran karena konsepsi belajar mengacu pada pandangan konstruktivistik, bahwa understanding construction adalah lebih penting dibandingkan dengan memorizing fact (Abdullah \& Abbas, 2006). Pemahaman merupakan proses mental yang memungkinkan terjadinya adaptasi dan transformasi ilmu pengetahuan (Gardner, 1999). Selanjutnya pemahaman muncul dari evaluasi diri sendiri (Wenning 2006). Konsekuensinya dalam mengemas suatu pembelajaran fisika adalah: 1) guru fisika dianjurkan untuk lebih banyak mengajak siswa untuk bereksperimen (Williams, 2005), dan 2) mengajar bukan berfokus pada how to teach tetapi hendaknya lebih berorientasi pada how to stimulate learning (Bryan, 2005) dan learning how to learn (Novak \& Gowin, 1985). 
Berdasarkan latar belakang masalah di atas, penelitian ini bertujuan untuk mengetahui seberapa banyak peningkatan Pemahaman Konsep dan Keterampilan Generik Fisika siswa kelas XII IPA1 SMA Negeri 4 Kota Bengkulu melalui model pembelajaran Induktif pada materi listrik-magnet.

\section{METODE PENELITIAN}

Penelitian ini dilaksanakan SMA Negeri 4 Kota Bengkulu. Desain penelitian yang digunakan adalah desain "One group pretest-posttest design". Subjek penelitian adalah kelas XII IPA1 berjumlah 32 orang yang terdiri atas 9 orang siswa laki-laki dan 23 orang siswa perempuan, yang terbagi kedalam kelompok atas (5 orang), kelompok menengah (20 orang), dan kelompok bawah ( 7 orang).

Data yang dikumpulkan dalam penelitian ini, mencakup: 1) pemahaman konsep, 2) kemampuan generic fisika; dan 3) respon siswa terhadap model pembelajaran. Teknik pengumpulan data menggunakan tes pemahaman konsep fisika (10 soal) dan tes keterampilan generik fisika (8 soal), masing-masing berbentuk esai. Agar diperoleh instrumen yang berkualitas dan dipercaya dilakukan uji panelis (antar rater) oleh 4 orang pakar yaitu dua orang dosen fisika dan dua orang guru fisika SMA. Kriteria untuk menentukan bahwa tes konsisten atau dapat dipercaya sebagai alat ukur jika nilai ICC (Intraclass Correlation Coefficients) pada anava Hoyt lebih besar dari 0,60. Hasil perhitungan anava uji rater menunjukkan nilai ICC $=0,853>0,60$ maka tes pemahaman konsep dikatakan reliabel sedangkan nilai ICC untuk tes keterampilan generik 0,84>0,60 sehingga tes keterampilan generic adalah reliable..

Data dalam penelitian ini dianalisis secara statistik deskriptif dengan menghitung nilai rata-rata dan standar deviasi. Peningkatan pemahaman konsep fisika antara sebelum dan sesudah pembelajaran dihitung dengan rumus $\mathrm{N}$-gain (gain score yang dinormalisasi), yaitu:

$$
g=\frac{S_{\text {post }}-S_{\text {pre }}}{S_{\max }-S_{\text {pre }}}
$$

dengan $S_{\text {pre }}=$ skor pre-test, $S_{\text {post }}=$ skor post-test; $S_{\max }=$ skor maximum. Tingkat perolehan skor kemudian dikategorikan ke dalam tiga kategori yaitu: Tinggi: $\mathrm{g}>0,7$; Sedang: $0,3 \leq \mathrm{g} \leq 0,7$; Rendah: g < 0,3 (Savinainen \& Scott, 2002). Untuk mengetahui tanggapan/respon siswa terhadap pembelajaran dengan menggunakan model induktif siswa diberikan angket sebanyak 10 pertanyaan.

\section{HASIL DAN PEMBAHASAN}

Gambaran pemahaman konsep siswa sebelum dan sesudah pembelajaran dapat dilihat dari peningkatan skor pretest terhadap skor posttest. Pada TABEL 1 disajikan rata-rata skor pretest dan skor posttest dengan standar deviasinya, serta N-gain tiap materi. Sedangkan TABEL 2 menyajikan rata-rata skor pretest, posttest, dan N-gain menurut indikator KGF.

TABEL 1. Rata-rata skor Pretest, Posttest, dan N-gain Pemahaman Konsep Tiap Materi

\begin{tabular}{llllllll}
\hline No. & Materi & & \multicolumn{3}{c}{ Rata-rata dan SD } \\
\cline { 4 - 6 } & & & & Pretest & Posttest & N-gain \\
\hline 1 & Medan magnet disekitar arus listrik & $(5$ & jam & 35,3 & 81,2 & 0,72 \\
& pembelajaran) & & 6,15 & 12,74 & \\
\hline 2 & Gaya magnetik pada penghantar berarus listrik & 35,3 & 81,2 & 0,71 \\
& & & 6,62 & 12,74 & \\
\hline 3 & Konsep induksi elektromagnet (7 jam pembelajaran) & 24,7 & 67,4 & 0,57 \\
& & & 6,62 & 9,94 & \\
\hline
\end{tabular}


TABEL 2. Rata-rata skor pretest, Posttest, dan N-gain Tiap Indikator Keterampilan Generik Fisika

\begin{tabular}{llccl}
\hline Kelompok & Indikator KGF & \multicolumn{2}{c}{ Rata-rata } \\
\cline { 3 - 4 } & & Pretest & Posttest & N-gain \\
\hline Atas & Bahasa Simbolik & 2,2 & 7,8 & 0,70 \\
$\mathrm{n}=5)$ & Hukum Sebab Akibat & 1,6 & 7,0 & 0,64 \\
& Inferensi logika & 1,8 & 7,6 & 0,70 \\
Rata-rata & Membangun Konsep & 2,0 & 7,4 & 0,67 \\
\hline Menengah & Bahasa Simbolik & & 6,2 & 0,53 \\
$(\mathrm{n}=20)$ & Hukum sebab akibat & 1,8 & 6,3 & 0,57 \\
& Inferensi logika & 1,4 & 6,0 & 0,54 \\
& Membangun Konsep & 1,2 & 6,5 & 0,58 \\
Rata-rata & 1,6 & & $\mathbf{0 , 5 5}$ (sedang) \\
\hline Bawah & Bahasa Simbolik & & 5,1 & 0,45 \\
$(\mathrm{n}=7)$ & Hukum sebab akibat & 1,1 & 5,7 & 0,51 \\
& Inferensi logika & 1,2 & 5,2 & 0,46 \\
& Membangun Konsep & 1,0 & 5,3 & 0,45 \\
Rata-rata & & 1,5 & & $\mathbf{0 , 4 6}$ (sedang) \\
\hline
\end{tabular}

Hasil penelitian menunjukkan bahwa pemahaman konsep fisika siswa memperoleh rata-rata nilai peningkatan berdasarkan gain yang dinormalisasi sebesar 0,67. Temuan penelitian ini sejalan dengan hasil penelitian sebelumnya (Prabawati, 2014; Warimun, 1996).

Dalam suatu ranah belajar, pemahaman merupakan prasyarat untuk tingkatan kemampuan kognitif yang lebih tinggi, aplikasi, analisis, sintesis, dan evaluasi (berdasarkan taksonomi Bloom).Kemampuan kognitif dalam aspek pemahaman melibatkan kemampuan berpikir tingkat tinggi termasuk kemampuan generik. Jadi pembelajaran untuk pemahaman sama dengan pembelajaran keterampilan berpikir.

Temuan penelitian terkait dengan pembelajaran pemahaman konsep dengan menggunakan model induktif memiliki implikasi bahwa untuk mencapai pemahaman konsep secara mendalam dalam belajar fisika, model pembelajaran induktif dapat diacu sebagai salah satu model pembelajaran.

Tabel 2 menyajikan rata-rata skor pretest, posttest, dan N-gain menurut indikator KGF.Model pembelajaran induktif dengan metode eksperimen yang diterapkan berhasil meningkatkan KGF.Indikator KGF yang dapat ditingkatkan dalam pembelajaran listrik magnet adalah bahasa simbolik, hukum sebab akibat, inferensi logika, dan membangun konsep.

Hasil penelitan menunjukkan ada peningkatan KGF. Hasil penelitian ini sejalan dengan penelitian penelitian yang dilakukan oleh Mahendri, dkk (2007).

Peningkatan keterampilan generik melalui pembelajaran dengan model induktif mempersyaratkan pemahaman konsep sebagai dasarnya, sehingga pemahaman konsep menjadi landasan untuk memperoleh keterampilan generik. Jadi dapat dikatakan bahwa pembelajaran model induktif dapat diacu sebagai pembelajaran untuk pembekalan KGF kepada siswa.

Respon siswa setelah mengikuti kegiatan pembelajaran dengan model induktif adalah baik, hal ini dibuktikan dengan jawaban yang dikemukakan terhadap sejumlah pertanyaan dalam angket. Siswa memberi respon positip akan ketertarikannya terhadap penggunaan model induktif dan metode eksperimen. Hal ini karena siswamerasa dilibatkan secara aktif untuk menemukan dan memahami konsep-konsep yang dipelajari, lebih berkonsentrasi dan banyak menggunakan pikirannya.

\section{KESIMPULAN}

Dari penelitian ini dapat disimpulkan bahwa: 1) Model pembelajaran induktif dapat meningkatkan pemahaman konsep siswa SMA pada materi listrik magnet dengan peningkatan sebesar N-gain = $0,67$; $)$ Model pembelajaran induktif dapat meningkatkan keterampilan generik fisika siswa SMA pada materi listrik magnet; dan 3) Respon siswa adalah dalam kategori baik. 


\section{UCAPAN TERIMAKASIH}

Ucapan terimakasih disampaikan kepada Bapak dan Ibu guru serta dosen fisika yang telah membantu menilai instrumen penelitian dan juga kepada SMA Negeri 4 Kota Bengkulu yang telah dijadikan lokasi penelitian.

\section{REFERENSI}

Abdullah, S. \& Abbas, M. (2006). The effect of Inquiry-Based Computer Simulation with Cooperative Learning on Scientific Thinking and Conceptual Understanding.Malaysian On Line Journal of Instructional Technology, 3(2), pp. 1-16.

Brotosiswojo, B.S. (2000). Hakikat Pembelajaran MIPA dan Kiat Pembelajaran Fisika di Perguruan Tinggi. Jakarta: Proyek Pengembangan Universitas Terbuka Dirjen Dikti, Depdiknas.

Bryan, J. (2005). Physics Activity for Family Math and Science Nights.Journal of Physics Teacher Education Online, 3(2), pp. 14-20.

Gardner, H. (1999). The Dicipline Mind: What All Students should Understan. New York: Simon \& Schuster Inc.

Joice, B \& Weil, M. (2011). Model of Teaching. Yogyakarta: Pustaka Pelajar.

Mahendri, Setiawan, A., Rusdiana, D. (2007). Model Pembelajaran Inkuiri Terbimbing pada Materi Keseimbangan Benda Tegar untuk Meningkatkan Penguasaan Konsep dan Keterampilan Generik Siswa SMA. Jurnal Penelitian Pendidikan IPA. 1 (2) pp. 115-122.

Novak, J. \& Gowin, D. (1985).Learning how to learn. Cambridge: Cambridge University Press.

Prabawati, R. (2014). Upaya Peningkatan Aktivitas dan Hasil Belajar Fisika Siswa melalui Penerapan Model Pembelajaran Berpikir Induktif pada Materi Kalor di Kelas X2 MAN 1 Model Kota Bengkulu.Skripsi Universitas Bengkulu: Tidak diterbitkan.

Savinainen, A. \& Scott, P. (2002). "The Force Concept Inventory.A Tool for Monitoring Student Learning”.Physics Education. 37(1), pp. 45-52.

Warimun, E.S. (1996). Efektivitas Model Pembelajaran Induktif dalam Meningkatkan Prestasi Belajar, Motivasi Berprestasi, dan Sikap siswa terhadap Pelajaran Fisika.Tesis pada PPS UPI Bandung: Tidak diterbitkan.

Wening, C.J. (2006). A Framework for Teaching The Nature of Science. Journal of Physics Teacher Education Online, 3(3), pp. 3-10.

William, G. (2005). Physics Teachers sould Put Pen to Paper and Write History.Journal of Physics Teacher Education Online, 40(3), pp. 24-33. 
